\title{
Stock Price Dynamics in Artificial Multi-Agent Stock Markets
}

\author{
A.O.I. Hoffmann, S.A. Delre, J.H. von Eije and W. Jager \\ Faculty of Management and Organization \\ University of Groningen \\ Landleven 5 \\ 9700 AV Groningen \\ The Netherlands \\ Email: a.o.i.hoffmann@rug.nl*
}

Reference:

Hoffmann, A.O.I., Delre, S.A., Eije, H. J. v., \& Jager, W. (2005). Stock Price Dynamics in Artificial Multi-Agent Stock Markets. In P.Mathieu, B. Beaufils, \& O. Brandouy (Eds.), Artificial Economics: Agent-Based Methods in Finance, Game Theory and Their Applications (pp. 191-201). Heidelberg: Springer Verlag.

\section{Introduction}

Worldwide financial markets have hit the news numerous times in the recent past due to the striking behavior of both (individual) investors active on these markets as well as the aberrant market developments that resulted from this aggregate investor behavior. In the last two decades, the two most obvious examples are the stock market crash of 1987 and the Internet bubble, and currently investors in Nano-technology may follow a hype (Surowiecki 2004; The Economist 2005).

Program trading, overvaluation and illiquidity could together explain part of the 1987 crash. The literature also suggests explanations for the Internet bubble, like the role of the media (Bhattacharya et al. 2004), processes of groupthink (Valliere and Peterson 2004), irrational exuberance (Shiller 2005), and overly optimistic expectations of the business prospects for companies active in this sector (Schleifer 2000).

Also computer-simulated markets with individual adaptive agents may be used in trying to explain observed market phenomena. A summary can be found in e.g., LeBaron (2000). These models range from relatively simple and straightforward (Day and Huang 1990; Lettau 1997), to more complex and revolutionary models

\footnotetext{
* The authors gratefully acknowledge T.L.J. Broekhuizen, J.J. Hotho and B. Lijnema for their useful comments on earlier drafts of this paper. The usual disclaimer applies.
} 
like the Santa Fe Artificial Stock Market of Arthur et al. (1997). The authors of this paper hope to contribute to the explanations of the observed financial market phenomena by incorporating social needs, social interactions and social networks of investors as introduced in Hoffmann and Jager (in press). The objective is to identify critical micro-level factors that drive investors' behavior and to explain macro-level phenomena that may be the result of aggregate micro-level investor behavior.

This paper is organized as follows. The second section describes the background of the study. The third section introduces the simulation model. The fourth and fifth sections are devoted to a number of simulation experiments. The sixth section discusses the results until now and indicates the limitations of the study as well as areas for future research.

\section{Background}

In addition to more financially oriented needs for e.g., monetary profits, investors may also strive to satisfy other, more social needs by the act of investing. For example, an environmentalist may satisfy three different needs by purchasing green stocks. First, he ${ }^{1}$ may obtain financial gains by doing so and in this way satisfy the need for subsistence (Max-Neef 1992). Second, he may satisfy a need to identify himself with green companies. Third, by investing in this company he may indirectly fulfill his need to participate with other environmentalists.

When investors try to satisfy needs that are more socially oriented, their decision-making behavior may also become more socially oriented and social interaction is expected to increase. Moreover, investors may then also be inclined to use the investing behavior of other investors as an input for their own decisionmaking or they may even simply copy that behavior (Deutsch and Gerard 1955; Hirschleifer 1993; Suls et al. 2002; Mangleburg et al. 2004). This does not imply that socially oriented decision-making only originates from social needs. Uncertainty, for example, may also be a driver of socially oriented behavior (Festinger 1954; Jones and Gerard 1967; DiMaggio and Louch 1998; Cialdini and Goldstein 2004). Socially oriented decision-making may, moreover, occur in social networks that connect friends with friends of friends and so on (Watts and Strogatz 1998; Watts 2001; Janssen and Jager 2003).

A practical example is expected to enhance the understanding of the way the above propositions may work out in investment practice. On Monday morning, investor Alpha comes to work and receives some interesting information on a publicly traded company. During a lunch meeting on the same day, he shares this information with acquaintances and colleagues. This people then might start to trade on this information. A friend of these friends, investor Beta, desires to belong to this group of investors and also purchases the stock. After a short period

\footnotetext{
${ }^{1}$ Whenever the authors for reasons of simplicity and consistency use male forms like 'he' or 'his', the reader can obviously substitute them for female forms like 'she' or 'her'.
} 
of time, investors trade either because of the company related information they received (social informative influence) or because they want to belong to the group of investing friends (social normative influence). At the end of the week, a formerly tranquil stock may be making headlines due to an unexpected increase in volatility.

We hypothesize that beta investors, that is investors who exhibit socially oriented decision-making, may ignite such aberrations. Recent research on (social) networks has demonstrated that many large networks display a scale-free powerlaw distribution for node connectivity (Barabasi and Albert 1999). In terms of market dynamics, this may imply that a small proportion of investors having many contacts, so-called 'hubs', may have an exceptional influence on the investing behavior of others. An approach that wants to explain market volatility over time might do wise to incorporate the concept of beta investors as well as the concept of networks.

\section{The simulation model}

As a first attempt to implement our framework, we start with the relatively simple model of investor behavior of Day and Huang (1990). In the model, investors can follow either a more fundamentally based "rational" strategy (called the $\alpha$ strategy) or a more socially based strategy (called the $\beta$-strategy). The $\alpha$-strategy is based on a comparison between the current price $\mathrm{p}$ and a given long-run investment value $u$. Whenever the market price is below the long-run investment value, the $\alpha$-investor buys. Whenever the market price is above the long-run investment value, the $\alpha$-investor sells. When the market price equals the long-run investment value, the $\alpha$-investor holds. This behavior is limited by a topping price $\mathrm{M}$ and a bottoming price $\mathrm{m}$. The $\beta$-strategy suggests more socially oriented behavior. $\beta$-investors buy when they expect an upward price trend (whenever the current price $\mathrm{p}$ is above a given current fundamental value $\mathrm{v}$ that initially equals $\mathrm{u}$ ) and sell when they expect a downward price trend (whenever $\mathrm{p}$ is below v). This kind of behavior is akin to herding behavior (see e.g., Orlean 1989; Scharfstein and Stein 1990; De Bondt and Forbes 1999; Bikhchandani and Sharma 2000; Cont and Bouchaud 2000; Hirschleifer and Teoh 2003; Banerjee and Fudenberg 2004; Lux 2004). The last participant on the market is the market maker. The market maker sets the market price according to the combined total excess demand or supply of the $\alpha$ - and $\beta$-investors.

The extent to which investors follow an $\alpha$-strategy or a $\beta$-strategy is weighted by the parameter $S$ that represents the social susceptibility of an investor. Stock markets and stocks alike may differ to the extent that investors focus more on fundamental characteristics of a share like price/earnings ratios and beta's, or focus more on social aspects of a share like information about which shares friends, colleagues or prominent finance experts buy. Different investors have different values of $\mathrm{S}$. That is, there is heterogeneity in the investors with regard to 
their strategies. Moreover, investors may change their $\mathrm{S}$ given the circumstances, which leads to dynamism in the strategies they use.

We can formalize the above in the following simple formula for total excess demand that is based on Day and Huang (1990):

$$
E=(1-S) \cdot(u-p) \cdot f(p)+S \cdot(p-v)
$$

Here $\mathrm{f}(\mathrm{p})$ is a weighting function that represents the chance of lost opportunity caused by either failing to buy when market prices are low or failing to sell when market prices are high.

\section{Simulation Experiments with Simultaneous Updating}

In the first series of simulation experiments, we tested for different values of $\mathrm{S}$. When $\mathrm{S}$ is very low or close to zero, indicating that fundamental traders dominate the market, we expect the price to stabilize and to remain at a constant level after a number of time steps. This equilibrium price, however, is higher than the starting price and the long-run investment value. So, the small proportion of $\beta$-investors did not succeed in pushing the market out of equilibrium into chaotic price behavior, but did induce an upward shock. In figure 4.1, we present an example of the price dynamics for this first series of experiments (with $\mathrm{p}=0.501 ; \mathrm{u}=0.500 ; \mathrm{S}$ $=0.03$ and 10 agents).

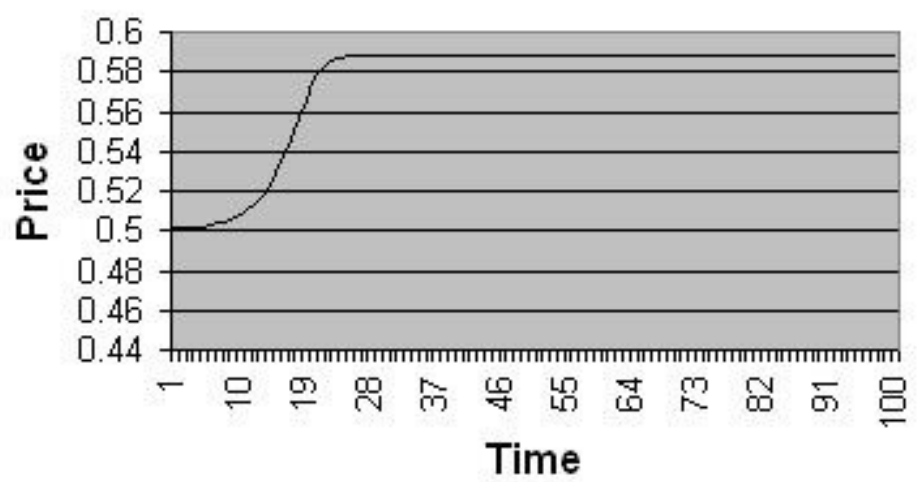

Fig. 4.1. Price series from experiment 1

In the second experiment we increased the number of agents, which resulted in more chaotic price dynamics as can be observed in real stock markets. However, increasing the value of $\mathrm{S}$ (i.e. the weighting of the $\beta$-strategy) has a similar effect. In figure 4.2 , we present an example of the price dynamics for this second series 
of experiments (with $\mathrm{p}=0.501 ; \mathrm{u}=0.500 ; \mathrm{S}=0.02$ and 100 agents). DurbinWatson tests and GARCH analysis indicated both autocorrelation and heteroscedasticity to be present in the price series from this series of experiments. Both effects can also be observed in real-life stock market returns. However, the distribution of returns was far from $(\log )$ normal, which is in contrast to the distribution of returns that are observed in the real stock markets.

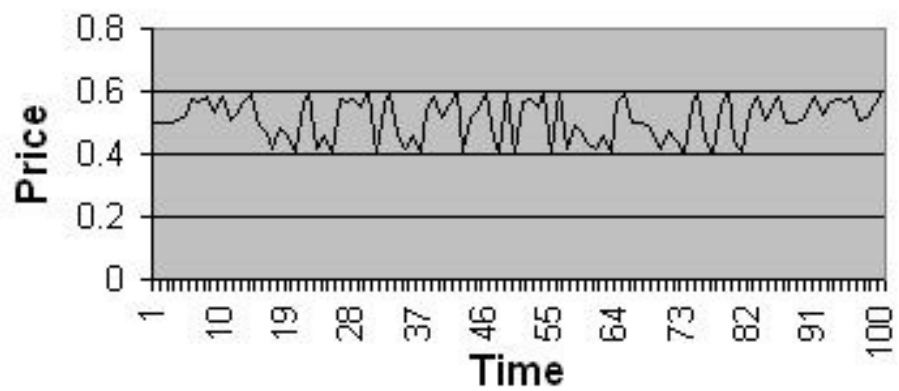

Fig. 4.2. Price series from experiment 2

In a further experiment, we increased the weighting of the $\beta$-strategy over certain boundaries, which leads to stock price dynamics that very quickly get out of bounds. In these situations, the price dynamics become so excessive, that we instructed the computer to stop the simulation. This is visible in figure 4.3 (where we used $\mathrm{p}=0.501 ; \mathrm{u}=0.500 ; \mathrm{S}=0.100$ and 100 agents) by the absence of price developments after a short period of very volatile stock price dynamics.

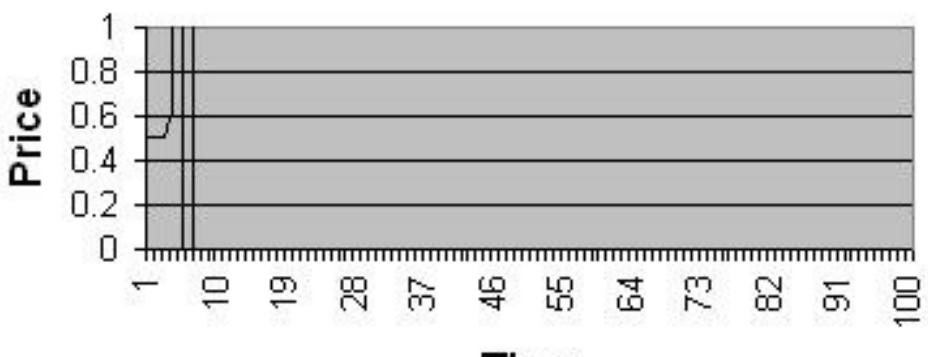

Time

Fig. 4.3. Price series from experiment 3 
In the first simulation experiments, the investors were homogeneous, i.e. $\mathrm{S}$ was set at a certain value and this value was the same for all investors. We hypothesized that as heterogeneity would be introduced in investors' strategies, market volatility would reduce. We expected that with heterogeneous agents, a higher average level of $\mathrm{S}$ would be needed to cause the same market volatility as found with homogenous agents. In further experiments, which will not be discussed here into detail, we introduced heterogeneity by not using one fixed average value of $S$, but using a range of randomly generated values of $S$ to lie within 0 and a set value. This situation would represent the actual market situation in a more realistic way, as it is a well-known fact that not all investors follow exactly the same strategy. Although this setting eventually resulted in the same average $S$ for the experiment as when directly setting $S$ at a certain average value, we expected a more balanced overall market behaviour, as different strategies may cancel each other out. However, simulation experiments that were performed with this adjusted setting demonstrated this effect to be only minor. This might have been caused by the fact that we did not introduce the social network yet and therefore there was no direct social interaction among investors.

\section{Simulation Experiments with Sequential Updating}

A persistent problem in the previous simulation experiments was that the parameter space for which useful price series, like those of figure 4.2, were obtained was very small. This problem was caused by the fact, that in the simulation model that we adapted from Day and Huang (1990), all investors made their decisions to buy, sell or hold at exactly the same moment in time. This is not realistic, as in real stock markets prices may be changing in response to the trades of individual market participants.

In order to mitigate this problem, we subsequently decided to use sequential updating of the market. Now, a random process is responsible for the order in which the investors are selected to make their decision. After each individual trade, the market is cleared and a new market price is calculated. Then, another investor trades, reacting partly to the trade of the other investor, as the price has now probably changed. In the following, we will report on a number of experiments that were performed after this change in the market updating mechanism.

In the fourth experiment, investors are still homogeneous, that is, they all have the same value of $S$. In this case, the price always reaches equilibrium. No matter how strong the $\beta$-strategy is, the $\alpha$-strategy is always able to bring the market to equilibrium, though at a higher level. However, the price level at which an equilibrium is reached depends on the value of $S$. Higher values of $S$ lead to equilibria at higher levels. In figure 5.1, the price developments for different levels of $\mathrm{S}$ are presented (with $\mathrm{p}=0.501 ; \mathrm{u}=0.500$ and 100 agents). 

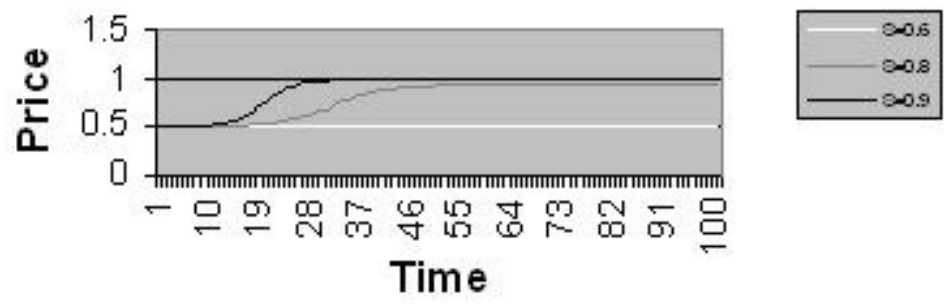

Fig. 5.1. Price series from experiment 4

In the fifth experiment, the investors are heterogeneous, with every investor having a different value for $\mathrm{S}$. This setting leads to a change in the price dynamics. Now, the price developments only become chaotic when the $\beta$-strategy is strong enough, that is, at higher levels of S. At relatively low levels of $S$, the price still reaches equilibrium. In figure 5.2, we report on the price developments that result from three different settings of $S$; randomly assigned between respectively 0 and $1,0.4$ and 1 and 0.5 and 1 . In the latter two cases, the graphs of the returns had distributions with a single top in the middle, though only the simulation where $\mathrm{S}$ was allowed to vary between 0.5 and 1 gave returns for which normality could not be refuted according to the Jarque-Bera test.

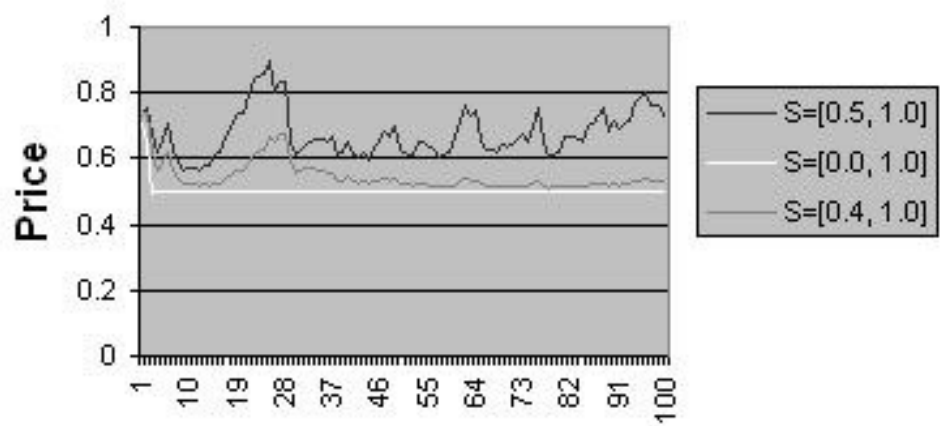

Time

Fig. 5.2. Price series from experiment 5

An ultimate requirement of stock market research is that one tries to explain outcomes in terms of real stock price data. Because traders that follow market developments (beta investors) may generate returns and risk fluctuations over time, we estimated the Garch $(1,1)$ equation (Brooks 2002) for the Dow Jones 
index over the period of September 7th until November 24th 2004 (57 daily observations). This represented a recent period without special holidays. We used dummies for days of the week (Monday till Thursday). The resulting constant term for each equation represented the expected returns on Friday. Table 5.1 indicates the estimated coefficients for the Dow Jones index, the concomitant variance equation as well as the results from experiment 5 with $S=[0.5,1.0]$ and $\mathrm{S}=[0.4,1.0]$ respectively.

Table 5.1. Arch and Garch estimates

\begin{tabular}{|c|c|c|c|c|c|c|}
\hline & \multicolumn{2}{|c|}{$\begin{array}{l}\text { Dow Jones } \\
\text { percentage } \\
\text { returns }\end{array}$} & \multicolumn{2}{|c|}{$S=\left[\begin{array}{lll}0 & 5,1 & 1\end{array}\right]$} & \multicolumn{2}{|c|}{$s=[0,4,1.0]$} \\
\hline & $\begin{array}{l}\text { Coeffi } \\
\text { cient }\end{array}$ & Prob. & $\begin{array}{l}\text { Coeffi } \\
\text { cient }\end{array}$ & Prob. & $\begin{array}{l}\text { Co eff } i \\
\text { cient }\end{array}$ & Prob. \\
\hline $\mathrm{c}$ & 0.269 & 0283 & 0.065 & 0.007 & 0.000 & 0845 \\
\hline MONDAY & -0.190 & 0.642 & & & & \\
\hline TUESDAY & -0.118 & 0.732 & & & & \\
\hline WEDHESDAY & -0091 & 0.756 & & & & \\
\hline THURSD AY & .0381 & 0.190 & & & & \\
\hline \multicolumn{7}{|c|}{ Variance Equation } \\
\hline c & 0.057 & 0.200 & 0.001 & 0.508 & 0.000 & 0.358 \\
\hline $\operatorname{RESID}(-1)^{\circ} 2$ & -0.150 & 0.066 & 0.306 & 0.059 & 0.503 & 0.000 \\
\hline GARCH(-1) & 1.025 & 0.000 & 0.803 & 0.000 & 0.610 & 0.000 \\
\hline \multicolumn{7}{|c|}{ Equation Statistics } \\
\hline Adj. R-squared & -0.151 & & -0.034 & & -0.034 & \\
\hline DW statistic & 1.716 & & 1923 & & 1.601 & \\
\hline
\end{tabular}

Then we compared these real life results with the outcomes of our simulations for at random allocated beta investors that gave price fluctuations over time (see figure 5.2 and table 5.1). Because our simulation results are rather arbitrarily chosen, we do not compare the estimated coefficients, but we like to refer to the similarity of the significances found for the Dow Jones index as well as our estimates based on randomly allocated beta investors (especially $S=[0.5-1.0]$ ) indicated with italics. The similarity of these findings suggest that Arch and Garch effects of real life stock markets might be attributed to beta investors that randomly enter the market. A next step in the research is therefore the remodeling of market participants' behavior in such a way that the behavioral outcomes mimic stock markets characteristics like mean return, risk, and the development of risk over time.

\section{Discussion}

In the experiments discussed in this paper, $\beta$-investors derived social information directly from the market. In subsequent simulation experiments, investors may also obtain (social) information from their social networks. They may observe the 
behavior of other investors in their social network and use this behavior as a benchmark for their own behavior.

In this paper, we did not include the arrival of new information on stocks in the market. However, we made some preliminary simulations by randomly changing the current fundamental value $\mathrm{v}$ of individual investors. This news creates turbulence in the market when investors are homogeneous and increases the turbulence when investors are heterogeneous.

In future papers we will report on the results of including the investor's social network in our multi-agent simulation model. Moreover, we will experiment with different network structures and different ways of introducing information on the long-run investment value $\mathrm{u}$ and the current fundamental value $\mathrm{v}$ in the network. As different network types have different information diffusion characteristics (Cowan and Jonard, 2003) we expect to reveal how different network structures affect stock market dynamics in different ways. Furthermore, varying the number of hubs and their importance as well as network sizes is expected to contribute to a better understanding of the role of social networks on investor behavior and stock market dynamics.

One limitation may remain in the model, even after incorporating sequential updating and news. This is that the market dynamics are generated by the actions of the investors, but the cognition of the investors is never affected by the evolution of the market. In order to make the model more interesting, we need to include a feedback mechanism that influences the decision making of the investors (Arthur 1994, 1995). An example of such a feedback mechanism might be that investors change their strategies according to the returns they get. 


\section{References}

Arthur W B (1994) Bounded Rationality and Inductive Behavior (the El Farol Problem). American Economic Review 84: 406-411

Arthur W B (1995) Complexity in Economic and Financial Markets. Complexity 1: 20-25

Arthur W B, Holland J, LeBaron B, Palmer R T P (1997) Asset pricing under endogenous expectations in an artificial stock market. In: Arthur W B, Durlauf S, Lane D (eds)The economy as an evolving complex system II. Addison-Wesley, Reading MA, pp 15-44

Banerjee A, Fudenberg D (2004) Word-of-mouth learning. Games and Economic Behavior 46: $1-22$

Barabasi A-L Albert R (1999) Emergence of scaling in random networks. Science 286: 509-512

Bhattacharya U, Galpin N, Ray R, Yu X (2004) The role of the media in the Internet IPO bubble.

Bikhchandani S, Sharma S (2000) Herd behavior in financial markets: a review. IMF Staff Papers 47: 279-310

Brooks, C (2002) Introductory Econometrics for Finance. Cambridge University Press, Cambridge, U.K.

Cialdini, R B, Goldstein, N J (2004) Social Influence: Compliance and Conformity. Annual Review of Psychology 55: 591-621

Cont R, Bouchaud J (2000) Herd behavior and aggregate fluctuations in financial markets. Macroeconomic dynamics 4: 170-196

Cowan R, Jonard N (2003) Network structure and the diffusion of knowledge. Journal of Economic Dynamics and Control

Day R H, Huang W (1990) Bulls, bears and market sheep. Journal of Economic Behavior and Organization 14: 299-329

De Bondt W F M, Forbes W P (1999) Herding in analyst earning forecasts: evidence from the United Kingdom. European Financial Management 5: 143-163

Deutsch M H, Gerard B (1955) A study of normative and informative social influences upon individual judgment. Journal of Abnormal and Social Psychology 51: 629-636

DiMaggio P, Louch H (1998) Socially embedded consumer transactions: for what kind of purchases do people most often use networks? American Sociological Review 63: 619637

Festinger L (1954) A theory of social comparison processes. Human Relations 7: 117-140

Hirschleifer D (1993) The blind leading the blind: social influence, fads and informational cascades. Finance 24

Hirschleifer D, Teoh S H (2003) Herd behaviour and cascading in capital markets: a review and synthesis. European Financial Management 9: 25-66

Hoffmann A O I, Jager W (in press) The effect of different needs, decision-making processes and network structures on investor behavior and stock market dynamics: a simulation approach. ICFAI Journal of Behavioral Finance

Janssen M A, Jager W (2003) Self-organisation of market dynamics: consumer psychology and social networks. Artificial Life 9

Jones E E, Gerard H B (1967) Foundations of social psychology. John Wiley and Sons, New York 
LeBaron B (2000) Agent-based computational finance: suggested readings and early research. Journal of Economic Dynamics and Control 24: 679-702

Lettau M (1997) Explaining the facts with adaptive agents: the case of mutual fund flows. Journal of Economic Dynamics and Control 21: 1117-1148

Lux T (2004) Herd behaviour, bubbles and crashes. The Economic Journal 105: 881-896

Mangleburg T F, Doney P M, Bristol T (2004) Shopping with friends and teens' susceptibility to peer influence. Journal of Retailing 80: 101-116

Max-Neef M (1992) Development and Human Needs, in P Ekins and M Max-Neef (eds), Real-life economics: understanding wealth creation. Routledge, London/New York

Orlean A (1989) Mimetic contagion and speculative bubbles. Theory and Decision 27: 6392

Scharfstein D S, Stein J C (1990) Herd behavior and investment. American Economic Review 80: 465-479

Schiller R J (2005) Irrational Exuberance. 2nd edn. Princeton University Press, New Jersey

Shleifer A (2000) Inefficient Markets: An Introduction To Behavioral Finance. Oxford University Press, New York

Suls J, Martin R, Wheeler L (2002) Social comparison: why, with whom, and with what effect? Current Directions in Psychological Science 11: 159-163

Surowiecki J (2004) The Financial Page: Bring on the nanobubble. The New Yorker 68

The Economist (2005) Beyond the nanohype. 366: 23-24. Valliere D, Peterson R (2004) Inflating the bubble: examining dot-com investor behaviour. Venture Capital 6: 1-22

Watts A (2001) A dynamic model of network formation. Games and Economic Behavior 34: $331-341$

Watts A, Strogatz S H (1998) Collective dynamics of 'small-world' networks. Nature 393: $440-442$ 